\title{
A RELAÇÃO URBANO/RURAL NO ESTATUTO DA CIDADE
}

\author{
José Luiz de Moura Filho ${ }^{1}$
}

\begin{abstract}
Resumo: O presente artigo avalia a tendência à padronização que os Planos Diretores vêm experimentando, a partir da edição do Estatuto da Cidade (Lei Federal 10.257/01). Esta lei trouxe uma série de instrumentos de indução ao desenvolvimento orientando a construção dos Planos Diretores no sentido da complementariedade campo-cidade. Ela reconhece que o território deixa de ser um referencial estático (setorial), adquirindo caráter mais dinâmico, enquanto suporte das relações sócio econômicas. No entanto, ela não leva em conta o aspecto cultural que envolve o uso da propriedade. Além disso, ignoram alguns planejadores que muitos dos núcleos urbanos têm características rurais, bem como zonas rurais sofrem enorme influência dos centros urbanos.
\end{abstract}

Palavras- chave: Estatuto da Cidade; Urbanismo; Campo-cidade; Territorialidade.

\section{The urban/rural relation on statute of city}

\begin{abstract}
This article discusses the trend toward standardization that City Master Plans are experiencing since the edition of the City Statute (Federal Law 10.257/01). This law has brought a series of instruments, which lead to the development and guided the construction of City Master Plans in the sense of rural-urban complementarity. It recognizes that the territory is no more a static (sectorial) frame, but it acquires a more dynamic characteristic as support of the socio-economic relationships. However, the City Statute does not take into account the cultural aspect that involves the use of the property. In addition, some planners ignore that many of the urban cores have rural features, as well as rural areas suffer enormous influence of urban centers.
\end{abstract}

Key-Words: City Statute, Rural-city, Territoriality.

\section{INTRODUÇÃO}

Há muito de mito no fenômeno da "urbanização", que teria caracterizado os últimos anos de crescimento das cidades, no Brasil e no mundo, dados os critérios mais variados para definir-se núcleo urbano, centro urbano, aglomeração urbana e tantas outras categorias daí advindas.

Tal mitologia fez com que emergisse no aparato de Estado a suposta necessidade não só de uma estrutura capaz de planejar, executar e avaliar medidas de contenção do

${ }^{1}$ Possui graduação em Direito pela Universidade Federal de Santa Maria (1988), onde é Professor Adjunto, vinculado ao Departamento de Direito, lecionando Direito Internacional Público e Direito Comunitário e da Integração, nos Cursos de Direito e Relações Internacionais, Direito Ambiental nos Cursos de Bacharelado e Licenciatura em Geografia, Teoria da Urbanização e Ateliê de Planejamento Urbano e Regional no Curso de Arquitetura e Urbanismo. É Mestre em Direito pela Universidade do Vale do Rio dos Sinos - UNISINOS (2001) e Doutor em Desenvolvimento Regional pela Universidade de Santa Cruz do Sul (RS), tendo feito Estágio no Exterior (sanduiche) com bolsa da CAPES, na UMINHO (Portugal), na área de Cooperação Transfronteiriça. Foi Chefe das Assessorias Jurídicas da FEPAM e METROPLAN, no período de 1999/2002. É consultor em Projetos de Extensão envolvendo minorias étnicas. Tem experiência na área de Direito, com ênfase em Direito Ambiental, Urbano e Internacional Público, atuando, principalmente nos seguintes temas: Licenciamento Ambiental, Planos Diretores e Regularização Fundiária de territórios quilombolas e indígenas. 
caos urbano, enquanto crescimento desordenado das cidades e, de consequiência, das periferias a elas adjacentes, como, também, de todo um arcabouço jurídico, como se a legislação tivesse o condão de, por si só, induzir a um comportamento mais conforme com a tão decantada sustentabilidade que vem pautando o tema meio ambiente.

Embora com mais de 40 anos, o Estatuto da Terra ainda dita as regras em termos de função social da propriedade, recepcionado que foi pela Constituição Federal brasileira de 1988, com as alterações que lhe impuseram leis posteriores. Já o Estatuto da Cidade, depois de quase uma década e meia de discussão no Congresso Nacional, veio estabelecer requisitos ao cumprimento, pela propriedade urbana, de sua função social, sem a qual não se a reconhece como tal e, pois, não se a protege.

No bojo deste, atribui-se à cidade funções sociais, o que não representa propriamente uma novidade, eis que desde os famosos CIAMs - Congresso Internacional de arquitetura moderna- já se debatia sobre o tema. O que de novo surgiu foi a constatação de que a categoria "cidade" é agora tratada muito mais do ponto de vista dinâmico/espacial do que estático/setorial.

Este paradoxo - cidades com características eminentemente rurais e localidades do campo em que, ou as atividades são tipicamente urbanas, ou a maior parte da população está assim empregada - está a ensejar dos planejadores urbanos e regionais uma postura menos preconceituosa no trato da questão, privilegiando, sempre, a qualidade de vida que, afinal, é o objetivo maior de toda intervenção planejada no território, afastando-se das tentações de reduzir o processo de planejamento a um padrão, como parece emanar, não só da legislação, mas, ainda, da postura mesma de tais profissionais, em busca da "estandardização" da cidade, como se fosse um produto.

\section{RURAL E URBANO NO BRASIL CONTEMPORÂNEO}

A mitificação do urbano é, de fato, fenômeno que toma dimensões inimagináveis, por força da globalização que passa a pautar o ritmo das relações sociais em um mundo reduzido - espacial e temporalmente - à virtualidade.

Ocorre, porém, que, por interesse do capital, não somente o "tempo é dinheiro", mas o espaço também passa a ser apropriado por meio de novas estratégias. Como relata Rizzardo (1991) resta claro que a propriedade imobiliária foi das primeiras manifestações do individualismo que caracteriza o homus aeconomicus, mas aqui 
estamos falando em privatização do espaço público, ou seja, da cidade como lócus de trocas não só materiais, mas também culturais e afetivas.

Remonta ao final da década de 1980, do século XX, um considerável deslocamento das populações rurais para a periferia das cidades, em especial em razão da mecanização no campo e a conseqüente redução do emprego, o que acaba por acrescentar à ilegalidade já praticada em larga escala pelo setor imobiliário especulativo, o caos - agora sim visível - da urbanização desordenada, daí decorrendo uma série de efeitos nefastos, do ponto de vista sócio-ambiental.

$\mathrm{Na}$ ânsia da solução fácil, lideranças populistas vão fomentar as emancipações como a tábua de salvação contra a centralidade do poder -, expediente que acaba por fazer emergir estruturas institucionais que não respondem - e nem correspondem - às reais necessidades das localidades. Pelo contrário, acentuam as dificuldades, uma vez que, aos recursos financeiros e técnicos necessários para fazer frente às demandas por serviços básicos, somam-se as despesas com custeio da máquina pública.

É assim que irão surgir uma série de municípios sem quaisquer características urbanas. Lembra Veiga (2007) que há inclusive o absurdo de, no Rio Grande do Sul, haver uma cidade na qual a população urbana é composta de apenas 18 pessoas. Por certo que este é o exemplo mais radical, mas na média, a esmagadora maioria dos municípios possui população inferior a 20.000 habitantes, limite previsto na Constituição Federal como mínimo para que um município seja obrigado a elaborar um Plano Diretor.

Agravando, ainda mais, a situação, o legislador infraconstitucional elencou outras situações em que tal instrumento é obrigatório, por razões particulares.

\section{O ESTATUTO DA TERRA E A FUNÇÃO SOCIAL DA PROPRIEDADE RURAL}

Por ocasião da promulgação da Constituição Federal de 1988, os artigos referentes à função social da propriedade rural foram imediatamente regulamentados, eis que os movimentos sociais no campo já se encontravam bastante consolidados, ainda que contidos pelo regime de exceção vigente desde 1964, reflexo, com certeza, das profundas transformações por que passava o mundo, com o crescente e constante deslocamento das populações, das áreas rurais para as áreas urbanas. 
Frise-se que, naquele ano, foi editado o Estatuto da Terra, Lei Federal 4.504/64, que, embora desatualizado, veio a ser recepcionado pela nova ordem constitucional, a qual teve os artigos 184 a 191 imediatamente regulamentos, dispondo, em seu artigo 186, que a propriedade rural cumpre com sua função social quando atende, simultaneamente, aos seguintes requisitos: aproveitamento racional e adequado, utilização adequada dos recursos naturais disponíveis e preservação do meio ambiente, observância das disposições que regulam as relações de trabalho e exploração que favoreça o bem- estar dos proprietários e dos trabalhadores.

Observa-se que o respeito aos aspectos ambientais é bastante frisado no dispositivo, no que é acompanhado pelas preocupações com a dignidade da pessoa humana, mais especificamente no que tange às relações laborais, já que a terra tem por vocação, na formação sócio-territorial brasileira, a produção de alimentos, caracterizando-se mesmo o Brasil por ser um dos maiores exportadores de grãos do mundo, muito embora a condição de produtor de produtos primários sem qualquer valor agregado seja alvo de críticas, absolutamente procedentes, tendo em vista o potencial de desenvolvimento. É na interpretação da natureza daqueles requisitos a serem preenchidos que reside a efetivação da mudança de paradigma - ou, no mínimo, desmistificação da dicotomia urbano/rural - na elaboração de políticas públicas para o desenvolvimento do espaço como um todo, passando-se a uma abordagem muito mais territorial do que setorial, no sentido da dinamicidade do primeiro aspecto, ou seja, não é por estar no campo que o homem é menos cidadão, sujeito, pois, de direitos fundamentais típicos dos aglomerados urbanos.

Para tanto, o Estatuto da Cidade determinou, em seu artigo $2^{\circ}$, VII, que ao elaborar o Plano Diretor, o Executivo deve estar atento à complementariedade entre campo e cidade, mas, infelizmente, aquele instrumento não vem contemplando tal imperativo, limitando-se a abordar o rural quase que somente quando o descreve enquanto tudo o que não é urbano, ou seja, na Lei do Perímetro Urbano, apegado ainda, ao paradigma setorial de desenvolvimento, negando, assim, o caráter dinâmico do território e de sua construção pelo elemento social que nele vive.

\section{O PLANO DIRETOR E A FUNÇÃO SOCIAL DA PROPRIEDADE URBANA}

Quanto à função social da propriedade urbana e da cidade, tal somente se deu em 2001, ou seja, mais de uma década após a promulgação da Carta Constitucional, através 
do advento da Lei Federal 10.257/01 - Estatuto da Cidade - que condiciona o cumprimento daquela à observância dos preceitos do Plano Diretor, enquanto instrumento básico de ordenamento do território municipal.

Vários foram os instrumentos estabelecidos em tal legislação, os quais somente poderão ser adotados através da instituição de um Plano Diretor - salvo raras exceções em especial no que tange à ocupação de vazios urbanos, eis que um dos objetivos fundamentais deste planejamento é que a cidade cresça para dentro, ou seja, que se otimize o uso dos equipamentos que compõem a infra-estrutura urbana, como redes de energia, comunicações, água e saneamento, evitando-se assim, a supressão de vegetação para uso do solo e a conseqüente extensão de ditas redes às custas dos contribuintes, ou seja, de todos os moradores da cidade.

É neste sentido que o Instituto Polis (2001) trata dos "instrumentos de indução ao desenvolvimento", sejam eles de natureza urbanística, fiscal ou tributária, destacando-se o "parcelamento compulsório", "IPTU progressivo no tempo", "outorga onerosa do direito de construir", "direito de superfície" e a "transferência do direito de construir", enquanto mecanismos de intervenção na propriedade privada que têm por fim condicionar o uso e ocupação do solo urbano a um verdadeiro processo de controle social, antes exercido apenas de forma administrativa.

Agora, então, encontra-se a propriedade desvinculada de seu caráter absoluto- o qual foi tratado pelo Código Civil brasileiro de 1916 como o direito de usar, fruir e dispor sem qualquer limite que não a vontade do proprietário- passando a pautar-se no princípio da "justa distribuição entre os ônus e benefícios" decorrentes da urbanização, como relata a legislação pertinente.

Assim, não mais se justifica que parcelas de terra urbanizada, valorizadas pela dotação de equipamentos públicos e comunitários (rede de energia, telefonia, água e saneamento, calçamento, iluminação, etc.) continuem a servir unicamente ao capital imobiliário especulativo, pois que esses mesmos melhoramentos foram implementados com os recursos oriundos da tributação a que está sujeito todo o cidadão, urbano e rural, sendo, então, indispensável que, na cidade, sejam melhor aproveitados e, no campo, inaugurem uma nova fase na vida republicana.

\section{O ESTATUTO DA CIDADE E A FUNÇÃO SOCIAL DA CIDADE}


O autodenominado Estatuto da Cidade - Lei Federal 10.257/01 - foi discutido e elaborado ao longo de mais de doze anos, e pautou-se por dois aspectos fundamentais: a justa distribuição dos ônus e dos benefícios da urbanização e a gestão democrática das cidades, na esteira dos novos princípios adotados pela nova Constituição Federal, que apontam para a superação da democracia representativa, à qual vão se agregar instrumentos destinados à efetiva participação popular nas decisões das questões de Estado, característica maior da democracia participativa.

A doutrina, através de Silva (2006), relata que os antigos CIAMs haviam definido como funções da cidade a habitação, a recreação, a circulação e a produção, parâmetros que foram sobremaneira ampliados, em especial em razão daquela mudança de paradigma de que antes falamos, consistente na apropriação do espaço como algo não mais estático (setorial), mas sim dinâmico (territorial).

Num primeiro momento após referidos eventos, o poder público passou a planejar a cidade não enquanto produtora de funções, e sim prestadora de serviços, mas aos poucos houve uma mudança de paradigmas, Lefebvre (2001) revelou que os aglomerados urbanos são muito mais que um local de trocas materiais/econômicas viés talvez ainda fruto da cidade como oriunda das praças de mercado - traduzindo-se em verdadeiro lócus da cidadania, ou seja, onde o convívio com os demais, ao mesmo tempo em que nos liberta para sermos mais um na multidão - e muitos, no mesmo lugar - nos aprisiona em convenções sociais que, uma vez inobservadas, fariam do caos urbano algo bem pior.

A teoria da funcionalização- que consiste em atribuir existência, validade e eficácia apenas aos institutos jurídicos que se legitimam pela veiculação de uma função social- dos direitos vai responder bem aos conflitos surgidos com o avanço do sistema capitalista, em especial no que tange à apropriação dos recursos naturais, mais precisamente o solo, no caso do espaço urbano, pois que a função primeira consistente na "habitação" acaba por se traduzir em condição para o exercício dos demais direitos fundamentais, mormente aqueles que se encontram na base das outras funções: por exemplo, não há como falar-se que a "casa é asilo inviolável do indivíduo", como relata a Constituição Federal no Título dos direitos e garantias fundamentais, se a pessoa mora na rua, sem qualquer proteção, assim, à sua integridade física e, de conseqüência, moral.

É assim que vão surgir novos instrumentos de intervenção no ambiente construído, como é o caso do "Estudo de Impacto de Vizinhança", traduzindo-se em verdadeiro mecanismo de controle social do crescimento da cidade, de forma a que os 
empreendimentos/atividades nela instalados o sejam de forma a não violar aquele mínimo de bem-estar tão indispensável à vida com qualidade, que esta nova cidade pretende garantir.

\section{AS CIDADES COM CARACTERÍSTICAS RURAIS}

Nas recentes experiências de construção de Planos Diretores, por força do disposto no Estatuto da Cidade, deparamo-nos com Municípios que, muito embora apresentem características eminentemente rurais, são considerados - de direito - como verdadeiras cidades, para as quais a legislação federal exige um Plano Diretor, o que vai gerar alguns paradoxos.

Se tomarmos como exemplo o Município de Faxinal do Soturno (RS), cuja exigência de PDDUA baseia-se no fato de tratar-se cidade com interesse turístico, vamos observar que é muito difícil delimitar-se um índice de aproveitamento mínimo, com vistas à caracterização de terreno subutilizado ou não utilizado, sobre o qual poderia vir a incidir o Parcelamento Compulsório, o IPTU progressivo no tempo, ou mesmo a Desapropriação, enquanto instrumentos de indução ao desenvolvimento. A explicação para se fato é aferida com o relatório das leituras comunitárias e atas das audiências públicas do Plano Diretor do Município de Itaara, onde nota-se, em se tratando de Município integrante da Quarta Colônia de Colonização Italiana, por uma questão cultural, vários lotes urbanos são usados para a implantação de hortas e criação de pequenos animais (galinhas, patos, coelhos, codornas, etc.)

Inviabilizar tais atividades - taxando-as de desconforme à função social da propriedade urbana - conforme trata Santos (2004), seria negligenciar os aspectos culturais como formadores da cidade, senão mesmo que negar a ocorrência de um circuito inferior da economia, consideravelmente importante para a subsistência dos moradores, muitas vezes sem acesso ao mercado desses bens, seja pela distância, seja pelo custo, sem falar no aspecto do lazer que o trato com a natureza propicia, em termos de saúde mental, tendo-se presente, sempre, que o objetivo maior dos Planos Diretores é a garantia de um mínimo de bem-estar para os habitantes das cidades, já tão impactados com os conflitos decorrentes da vida em sociedade.

Por outro lado, a mesma baixa densidade demográfica que propicia a efetivação de princípios tais como o da "gestão democrática da cidade" - dado que os fóruns construídos para tanto poderão contar com significativa representatividade e, pois, 
legitimidade - repele a aplicação de instrumentos como a "outorga onerosa do direito de construir", em razão da relação deste justamente com a ocorrência de alta densidade demográfica, o que demonstra que condicionar a adoção de alguns instrumentos de indução ao desenvolvimento previstos no Estatuto da Cidade, à existência de Plano Diretor, é negar a diversidade dos aglomerados urbanos brasileiros e a riqueza de suas experiências.

\section{URBANIZAÇÃO E URBANIFICAÇÃO DE ÁREAS RURAIS}

Já em outros municípios, o que se vislumbra é justamente o contrário, como é o caso de Itaara (RS), o qual apresenta como característica mais visível, a ocorrência de Condomínios Fechados, fruto de antigos balneários, instalados sob a forma de clubes, quando a cidade ainda pertencia a Santa Maria (RS), constituindo-se, então, em Distrito.

Ou seja, tem-se aí uma cidade que já nasce guetificada, encontrando a coletividade - por ocasião das Leituras Comunitárias e Audiências Públicas considerável resistência dos moradores destes redutos que, em nome de uma suposta segurança, fazem com que os demais tenham que empreender enormes deslocamentos a pé, eis que não existe sistema de transporte coletivo, sequer público - para acessar suas moradias e os equipamentos urbanos e comunitários.

Ora, a legislação brasileira não contempla tal modalidade de parcelamento do solo, havendo tão somente a previsão de Loteamentos e Desmembramentos, tratando-se os Condomínios Fechados de verdadeiro esbulho fundiário - além de político, dado o poder dos Síndicos em tais enclaves - de áreas públicas, senão mesmo que representam verdadeira violação do princípio basilar do Direito Urbanístico, insculpido no Estatuto da Cidade, consistente na justa distribuição dos ônus e benefícios da urbanização, entre os habitantes da cidade, na medida em que estes são dispensados da destinação de áreas públicas, exigidas dos loteadores e desmembradores.

Por outro lado, na Conferência da Cidade, que encerrou o processo de construção do Plano Diretor, ficou flagrante que a dependência de Santa Maria (RS), em termos de comércio e prestação de serviços, era um dos aspectos que mais incomodavam os habitantes do Município, desconforto verbalizado na falta de um “centro" em Itaara (RS), aspecto que, numa visão mais técnica, é extremamente segregador, traduzido nas reiteradas espacializações centro/periferia, sempre atacado, e que, neste caso, poderá ser potencializado, não só a partir do sentimento manifestado pela população consultada mas, também e fundamentalmente, em razão de que a zona 
urbana do município é composta de 16 comunidades, dentre as quais uma área mais central, justamente onde se encontra o maior número de balneários, cujos moradores, na sua esmagadora maioria, são não residentes que, contrariando toda a lógica da gestão pública, valem-se do pouco de infra-estrutura e serviços básicos existentes.

\section{CONSIDERAÇÕES FINAIS}

Não se tem maiores informações acerca dos motivos que levaram o legislador constitucional, que trata do assunto em capítulo específico a despeito da política urbana, a fixar a população em 20.000 habitantes como limite mínimo à exigência de um Plano Diretor, o que difere dos demais requisitos impostos pela legislação infraconstitucional para que outras localidades também sejam obrigadas a elaborá-los, como aquelas consideradas como de interesse turístico - caso das duas analisadas no presente ensaio eis que, em se tratando de local com atrativos que façam com que haja significativo afluxo de pessoas, em épocas mais ou menos previsíveis, indispensável um mínimo de planejamento.

Ocorre que num país com dimensões continentais como o Brasil, com enormes diferenças sociais e regionais, tentar estabelecer um padrão de planejamento é tarefa, além de extremamente difícil, improdutiva, pois já está provado que a legislação, por si, não tem o condão de provocar mudanças significativas em termos de ordenamento do território, podendo, quando muito, condicionar algum comportamento excessivamente concentrador e especulativo de terra urbanizada, sendo mesmo relativo este conceito, como tantos outros nesta seara.

Segundo o "Texto Base" da 3a Conferência Nacional das Cidades, mesmo após uma série de avanços na cultura do planejamento, o maior desafio ainda é reverter a forma excludente com que as cidades são produzidas, contrariando tudo quanto já se conquistou e se alterou nesta lógica, nos últimos seis anos, ou seja, desde o advento do novo marco legal, o Estatuto da Cidade.

Talvez o problema não esteja tanto no aspecto da legitimidade da construção do processo, posto que, no caso de Itaara (RS), por exemplo, a participação popular ficou em torno de $7 \%$ da população, o que é significativo para uma cidade tão dispersa, espacialmente, e com uma população tão carente de mobilidade, mas sim relacionado a uma percepção setorial e não territorial da gestão municipal, que faz com que o planejamento de políticas públicas sofra do mesmo preconceito reinante quando o tema 
é o "campo", sempre confundido com o "agrícola", relegando-se, assim, a segundo plano os aspectos da ruralidade, característica maior de mais de $90 \%$ dos municípios brasileiros.

\section{REFERÊRNCIAS BIBLIOGRÁFICAS:}

BRASIL. Constituição da República Federativa do Brasil de 1988. Disponível em: <http://www.planalto.gov.br/ccivil_03/constituicao/Constituicao.htm>. Diário Oficial [da] República Federativa do Brasil, Brasília, DF, 05 out 1988

CAIXA ECONÔMICA FEDERAL E INSTITUTO PÓLIS. Estatuto da Cidade: guia para implementação pelos municípios e cidadãos. Brasília, 2001.

CONSELHO DAS CIDADES (Brasil). Ministério das Cidades. $3^{\text {a }}$ Conferência Nacional das Cidades, Texto Base.

LEFEBVRE, Henry. O direito à cidade. São Paulo: Centauro, 2001.

BRASIL. Lei Federal no 10.257 de 10 de julho de 2001. Regulamenta os arts. 182 e 183 da Constituição Federal, estabelece diretrizes gerais da política urbana e dá outras providências. Diário Oficial União, Brasília, DF, 1 de julho de 2007.

Lei Federal $n^{\circ} 3.071$ de $1^{\circ}$ de janeiro de 1916, revogada pela Lei $n^{\circ} 10.406$, de 10 de janeiro de 2002. Diário Oficial União, Brasília, DF, 05 de janeiro de 1916.

Lei Federal no 4.504 de 30 de novembro de 1964. Dispõe sobre o Estatuto da Terra, e dá outras providências. Diário Oficial União, Brasília, DF 31 de novembro 1964, retificado em 17 de dezembro de 1964 e em 6de abril de 1965.

Relatórios das Leituras Comunitárias e Atas das Audiências Públicas, constantes do Projeto de Extensão Plano Diretor Municipal de Itaara, desenvolvido por equipe multidisciplinar da UFSM (2006/2007), financiado pelo CNPq.

RIZZARDO, Arnaldo. Direito das Coisas. Rio de Janeiro: Aide Editora, 1991, p.235. SANTOS, Milton. O espaço dividido. São Paulo: Edusp, 2004.

SILVA, José Afonso da. Direito Urbanístico Brasileiro. São Paulo: Malheiros Editroes, 2006.

UNIÃO DA SERRA, conforme José Ely da Veiga in Mudanças nas relações entre espaços rurais $\boldsymbol{e}$ urbanos(http://www.econ.fea.usp.br/zeeli/Livros/2007_b_MUDANCAS_RUR_URB.pdf. www.mma.gov.br. 